\title{
Reliability of the Italian version of the International Spinal Cord Injury Pain Basic Data Set
}

\author{
G. Stampacchia ${ }^{1}$ A. Massone ${ }^{2} \cdot$ A. Gerini ${ }^{1} \cdot$ E. Battini ${ }^{3} \cdot$ S. Mazzoleni $\circledast^{3} \cdot$ Research Partners
}

Received: 3 November 2017 / Revised: 12 June 2018 / Accepted: 12 June 2018 / Published online: 24 August 2018

(c) International Spinal Cord Society 2018

\begin{abstract}
Study design Multicentric prospective psychometric study.

Objective To provide a translation of the International Spinal Cord Injury Pain Basic Data Set (ISCIPBDS) for Italian persons and to evaluate the interrater reliability of the translated version.

Setting Ten Italian rehabilitation centres specialized in spinal injury care.

Methods The initial translation was performed by two medical doctors who had an in-depth knowledge of spinal cord injury (SCI), and then a back translation (from Italian to English) was given to an accredited agency. Sixty-six participants with SCI (53 men, 13 women; mean \pm SD age: $53.4 \pm 16.0$ years) were evaluated by means of the Italian version of the ISCIPBDS by two different examiners. Intraclass correlation coefficient (ICC) or Cohen's Kappa $(\kappa)$ was calculated to test the interrater agreement for the test-retest cases.

Results All 66 participants had at least one pain problem and 34\% of them had only one type of pain. A good interrater agreement was obtained in terms of number of pain $(\mathrm{ICC}=0.781)$, type of pain $(\kappa=0.683)$, pain intensity $(\mathrm{ICC}=0.798)$, correspondence of pain localization $(\kappa=0.750)$, and the value of the pain interference in day-to-day activities, overall mood and night's sleep (ICC $=0.827$, ICC $=0.861$ and ICC $=0.724$, respectively). Eventually a prominent prevalence of neuropathic pain was recorded (64\% from the first examiner and $62 \%$ from the second one).

Conclusions The authors propose the Italian version of ISCIPBDS that can be used for research and clinical evaluation of pain in SCI persons; it shows a significant interrater reliability.
\end{abstract}

\section{Introduction}

A global-incident rate is estimated at 23 traumatic spinal cord injury (SCI) cases per million (almost 180,000 cases per annum). Regional data are available from North

Members of the Research Partners group are listed at the end of the paper.

Electronic supplementary material The online version of this article (https://doi.org/10.1038/s41393-018-0171-2) contains supplementary material, which is available to authorized users.

G. Stampacchia

g.stampacchia@ao-pisa.toscana.it

1 Spinal Cord Injury Unit, Pisa University Hospital, Pisa, Italy

2 Spinal Unit, Pietra Ligure Public Hospital, Savona, Italy

3 The BioRobotics Institute, Scuola Superiore Sant'Anna, Pontedera, Pisa, Italy
America (40 per million), Western Europe (16 per million) and Australia (15 per million) [1].

Among first-year survivors, overall 40-year survival rates were 47 and $62 \%$ for persons with tetraplegia and paraplegia, respectively [2].

Chronic pain is common after SCI and it is a considerable problem for most of the SCI patients, who often declare one or more types of chronic pain [3-8]. This aspect can significantly impact on functional ability, mood, independence, psychological well-being, life satisfaction and quality of life of persons with SCI [9-14].

Two kinds of pain are known: nociceptive and neuropathic. They present quite different clinical aspects and recognize different neuro-physiopathological origin: the former is a physiological response to nociceptors stimulation and it has a defensive function, the latter is an abnormal sensation due to pathological activation of the nervous system caused by neurological lesions; spontaneous action potentials of peripheral nerve fibres contribute to the neuropathic pain $[15,16]$. 
The neuropathic pain is the most common type of chronic pain in SCI people, and it is usually felt at or below the level of the injury [17].

Pain information records in a standardized way are useful for clinical treatment decisions concerning the pain condition and for evaluating the clinical outcomes of treatments in a consistent manner. Moreover, using comparable sets of clinical outcome measures would facilitate research collaboration between clinical centres and this consequently would increase efficiency of pain treatments. Then, the use of standardized sets of outcomes could improve the management of SCI-related pain.

The International Spinal Cord Injury Pain Basic Data Set (ISCIPBDS) was developed to standardize reporting of pain in SCI population to evaluate and compare results of different clinical centres [18].

The items in the ISCIPBDS investigate about: pain type, average pain intensity and interference, location, frequency, duration and its impact on physical, social and emotional functions and sleep [18].

ISCIPBDS aims to investigate the three worst pains of a person with a clear distinction between nociceptive and neuropathic pain, in contrast to other scales focused on the neuropathic pain evaluation; in these scales pain localization is poorly analysed [19-23]. On the other hand, this important aspect is deeply explored in the ISCIPBDS; in addiction, it provides information on pain intensity and the pain impact on day-to-day activities, mood and sleep interference.

On the other hand, the evaluation of pain localization is considered in the Mc-Gill Pain Questionnaire. [24]. It includes an accurate evaluation of pain characteristics, but there is no distinction between neuropathic and nociceptive pain.

The characteristic of the ISCIPBDS makes it an in-depth tool for research studies, but also useful in clinical practice.

The aim of the present study was to provide a translation of the ISCIPBDS for Italian people and evaluate the interrater reliability of the translated version.

\section{Methods}

\section{The Italian translation of ISCIPBDS}

Both International SCI Core Data Set and ISCIPBDS second version were translated from English to Italian [25]. The translation procedure was performed according to the recommendations of the International Spinal Cord Society [26]. The forward translation from English to Italian was performed by two medical doctors who had an in-depth knowledge of SCI and fluency in English. Then a back translation was committed to an English-speaking expert in medical language and fluency in Italian. Eventually a comparison of the original English version with the back translation version demonstrated the reliability of the Italian version: at the end the two English versions proved to be the same.

\section{Recruitment of participants}

Ten Italian rehabilitation centres specialized in SCI care participated in the study for six months (from September 2015 to February 2016). The hospital centre participation and patients' recruitment was on voluntary basis. In each centre, at least five SCI persons affected by pain were recruited for the study. They were both in-patients and outpatients. Inclusion criteria were: (1) both traumatic and nontraumatic SCI; (2) patients' pain related to SCI; (3) adult age ( $\geq 18$ years old); (4) preserved cognitive functions; (4) native Italians; (5) signed informed consent. Exclusion criteria were: (1) multiple sclerosis; (2) neoplastic disease. The Italian translation of ISCIPBDS was utilized to evaluate the patients' pain. Each SCI person could have one or more different pains, and every single worst different pain was analysed by means of the ISCIPBDS scale. Each of the recruited patients received a double evaluation from two different physicians, within $48 \mathrm{~h}$. The two physicians who administered the test for pain evaluation were part of the clinical staff involved in patients' care and each centre supplied two different evaluators. To record the personal data (age, gender), the time of spinal cord lesion, the days of hospitalization, the characteristics of the lesions (aetiology, American Spinal Injury Association (ASIA) Impairment Scale (AIS) [27]), other associated lesions, the spinal surgery and eventually the respiratory condition at hospital discharge and destination at discharge, the International SCI Core Data Set was used. All the tests recorded from the ten clinical centres were sent to the coordinator centre (Spinal Cord Unit, Pisa University Hospital) to be analysed.

\section{Statistics}

Intraclass Correlation Coefficient (ICC) or Cohen's Kappa $(\kappa)$ was calculated to test the interrater agreement for the test -retest cases. An ICC higher than 0.70 was considered 'reliable'. A $\kappa$ value higher than 0.60 was defined as 'good' agreement. All analyses were computed using SPSS 20.0 (IBM Corp., Armonk, NY, USA).

\section{Results}

The coordinator centre received one International SCI Core Data Set sheet and from 1 to 3 ISCIPBDS sheets for each of the 66 recruited patients; the tests were posted by ten participants centres (Pisa University Hospital, Pietra Ligure 
Public Hospital, Pavia Institute of Rehabilitation I.R.C.C.S, Montecatone Institute of NeuroRehabilitation, Sondalo Public Hospital, Cagliari Public Hospital, Firenze University Hospital, Catania Public Hospital, Perugia University Hospital, Alessandria Public Hospital).

The recruited SCI persons were $80 \%$ males (53/66) and $20 \%$ females (13/66). Patients were also characterized by age, between 19 and 84 years. The mean \pm SD age was 53.9 \pm 15.7 (Median 58, IQR 42.25-66.75).

The time after acute lesion at the current evaluation ranged from 1 to 342 months, mean $\pm \mathrm{SD}, 43 \pm 78$ (Median 8, IQR 4.00-38.00).

Spinal cord lesions were motor complete in 53\% and incomplete in $47 \%$ of cases: AIS A $41 \%$, AIS B $12 \%$, AIS C $26 \%$ and AIS D 21\%; an equal number of paraplegic $(50 \%)$ and tetraplegic $(50 \%)$ persons were observed. There were more traumatic $(60 \%)$ than nontraumatic $(40 \%)$ lesions. Among the traumatic aetiology, road traffic accidents were prevalent (51\%), followed by falls (36\%) and sport accidents (13\%). A vertebral fracture was associated to the spinal cord lesion in $65 \%$ of cases and skeletal muscle lesions in others body sites due to the trauma resulted in $48 \%$ of cases.

Thirty-four per cent of the recruited patients had only one type of pain, the other patients reported 2-5 different types of pain. All 66 patients affected by pain received two evaluations from two different physicians and a good correspondence on the number of pains recorded between the two physicians was found ( ICC $=0.781$ ) (Table 1).

A prominent prevalence of neuropathic pain was recorded $(64 \%$ from the first examiner and $62 \%$ from the second one), and the worst-pain intensity was declared from SCI persons to the two examiners, with the same value of intensity: mean \pm SD, $6.3 \pm 2.1$ (Median 6, IQR 5.00-8.00).

The $\kappa$ value of the type of pain between the two examiners was 0.683 . The ICC value on the pain intensity resulted in a value of 0.798 (Table 2).

The correspondence of pain localization between the first and the second examiners was studied: 48 pain localizations were the same in the two recordings (73\%), 18 were

Table 1 Number of reported pains by the first and the second examiners (ICC 0.781)

\begin{tabular}{lllrrrrr}
\hline & \multicolumn{4}{l}{ First examiner } & & \multirow{2}{*}{ Total } \\
\cline { 2 - 6 } & & 1 & 2 & 3 & 4 & 5 & \\
\hline Second examiner & $\mathbf{1}$ & $\mathbf{2 3}$ & 3 & 1 & 0 & 0 & 27 \\
& $\mathbf{2}$ & 1 & $\mathbf{1 2}$ & 3 & 0 & 0 & 16 \\
& $\mathbf{3}$ & 0 & 4 & $\mathbf{1 5}$ & 0 & 2 & 21 \\
& $\mathbf{4}$ & 0 & 1 & 0 & $\mathbf{0}$ & 1 & 2 \\
& $\mathbf{5}$ & 0 & 0 & 0 & 0 & $\mathbf{0}$ & 0 \\
& Total & 24 & 20 & 19 & 0 & 3 & $\mathbf{6 6}$ \\
\hline
\end{tabular}

different $(27 \%) ; \kappa$ coefficient was 0.75 . The nociceptive pain localization more frequently declared was chest-back: $46 \%$ to the first examiner and $52 \%$ to the second examiner. The neuropathic pain localizations more frequently declared were chest-back and lower limbs: respectively 34 and $38 \%$ to the first examiner and 22 and $39 \%$ to the second examiner (Fig. 1).

Out of the 48 cases having the same pain location of worst pain in two repeated evaluations, ten cases reported a second pain in one of the two evaluations; this was located near the worst pain, except in one case where the worst pain was on the upper back and the second pain on the upper leg.

The values of the pain interference in day-to-day activities, overall mood and night's sleep reported by the two examiners were similar: the ICC value was $0.827,0.861$ and 0.724, respectively (Table 3 ).

\section{Discussion}

The interrater reliability of the Italian version of ISCIPBDS version 2.0 has been demonstrated in this work on a sample of the SCI population, representative of Italian SCI persons [25]. Indeed, ten Italian centres specialized in SCI rehabilitation contributed to the study, each recording the Italian version of pain scale administrated to at least five SCI persons with pain twice from two different examiners who were physicians employed for SCI persons care.

The demographic results are coherent with the data recorded by SCI population: a ratio of male:female of $4: 1$; the mean age is higher $(53.4 \pm 16.0$ years old $)$, nearest to the sample SCI population with pain $(48.4 \pm 14.1$ years old $)$ resulted from a published study on SCI persons with pain, than to the sample of SCI population in an Italian multicenter epidemiologic study on all SCI persons (with and

Table 2 Worst-pain intensity reported by the first and the second examiners assessed by using a $0-10$ points numeric rating scale (NRS) $(\mathrm{ICC}=0.798)$

\begin{tabular}{llllllllllll}
\hline & \multicolumn{10}{c}{ NRS Score (First examiner) } \\
\cline { 2 - 11 } $\begin{array}{l}\text { NRS Score (Second } \\
\text { examiner) }\end{array}$ & $\mathbf{1}$ & $\mathbf{0}$ & 0 & 0 & 0 & 0 & 0 & 0 & 0 & 0 & 0 \\
& $\mathbf{2}$ & 0 & $\mathbf{0}$ & 2 & 0 & 0 & 0 & 1 & 0 & 0 & 0 \\
& $\mathbf{3}$ & 0 & 0 & $\mathbf{2}$ & 1 & 0 & 0 & 0 & 0 & 0 & 0 \\
& $\mathbf{4}$ & 0 & 0 & 2 & $\mathbf{3}$ & 2 & 0 & 1 & 0 & 0 & 0 \\
& $\mathbf{5}$ & 0 & 0 & 0 & 1 & $\mathbf{4}$ & 1 & 0 & 1 & 0 & 0 \\
& $\mathbf{6}$ & 0 & 1 & 0 & 1 & 1 & $\mathbf{1 0}$ & 1 & 0 & 0 & 0 \\
& $\mathbf{7}$ & 0 & 0 & 0 & 0 & 0 & 3 & $\mathbf{6}$ & 2 & 0 & 0 \\
& $\mathbf{8}$ & 0 & 0 & 0 & 0 & 1 & 0 & 2 & $\mathbf{5}$ & 3 & 0 \\
& $\mathbf{9}$ & 0 & 0 & 0 & 0 & 0 & 0 & 1 & 0 & $\mathbf{1}$ & 1 \\
& $\mathbf{1 0}$ & 0 & 0 & 0 & 0 & 0 & 0 & 1 & 1 & 0 & $\mathbf{4}$ \\
\hline
\end{tabular}




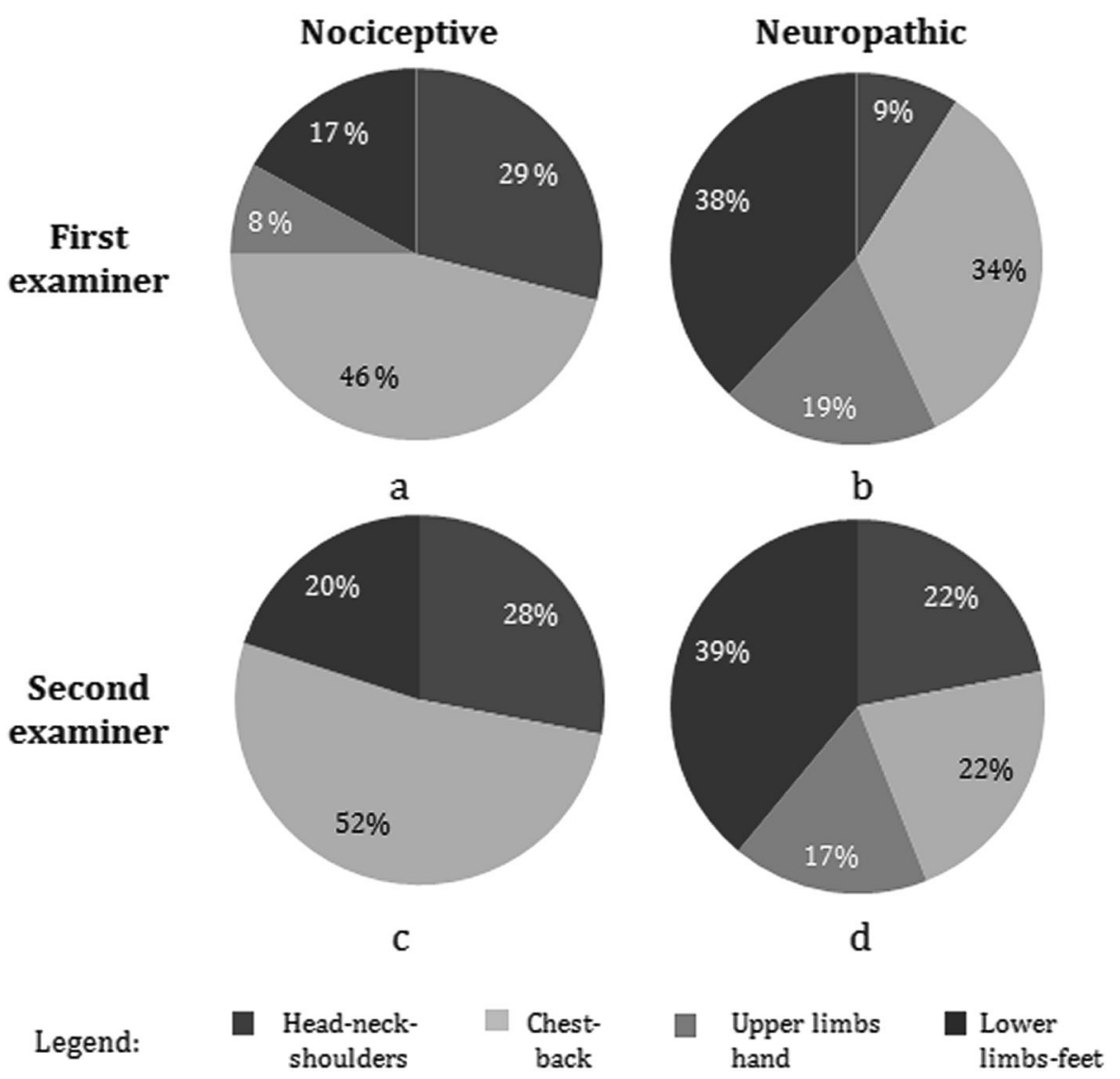

Fig. 1 Left column: nociceptive pain localization reported by the first examiner (a) and the second examiner (c). Right column: neuropathic pain localization reported by the first examiner $(\mathbf{b})$ and the second examiner $(\mathbf{d})$

Table 3 Pain interference by the first and the second examiners on day-to-day activities, overall mood and night's sleep assessed by using an NRS $0-10$ points scale

\begin{tabular}{lccc}
\hline Pain interference & First examiner & Second examiner & $\begin{array}{l}\text { ICC } \\
\text { value }\end{array}$ \\
\hline $\begin{array}{l}\text { Day-to-day } \\
\text { activities }\end{array}$ & $5.48 \pm 2.48[5.00]$ & $5.02 \pm 2.67[5.00]$ & 0.827 \\
Overall mood & $5.40 \pm 2.81[6.00]$ & $5.14 \pm 2.97[5.00]$ & 0.861 \\
Night's sleep & $4.42 \pm 2.92[5.00]$ & $4.30 \pm 2.97[5.00]$ & 0.724 \\
\hline
\end{tabular}

Values are expressed as mean \pm standard deviation [median]

without pain) $[28,29]$. This difference could be explained by higher age of persons with SCI affected by pain than the not affected ones; in addition, we should consider that an increased mean age of SCI persons has been demonstrated in last 20 years [28-33]. In this study, the time of acute spinal cord lesion is covering a large range of time (from 1 month to 28.5 years) because the test was done on both inpatients (which are prevalent in the post-acute stage) and out-patients visiting during follow-up or during medical complications. The wide care setting range allows the use of the validated scale in all persons with SCI.
The sample of persons with SCI examined includes both complete and incomplete cases, persons with paraplegia and tetraplegia in almost equal numbers. The prevalence of traumatic lesions on nontraumatic ones reflects the fact that most of the rehabilitation centres participating in the patient recruitment are Spinal Units which, in Italy, are mainly involved in traumatic SCI care, as the proportion of traumatic $(60 \%)$ and nontraumatic SCI $(40 \%)$ resulting is the present study is similar to previous study results on Italian SCI epidemiology $(67.5 \%$ with a lesion of traumatic and $32.5 \%$ of nontraumatic etiology) [28]. In Italy, most people 
with a traumatic SCI are admitted to a Spinal Cord Injury Unit, but only some with nontraumatic SCI after the acute phase (in-patients in neurology or internal medicine department) are hospitalized in nonSCI -specialized rehabilitation centres [29, 33, 34].

The high percentage of more than one pain and the predominance of neuropathic pain type confirm the results of other recent studies [35]. Only one visceral pain was found in this Italian study, different results are reported for Swiss [36].

Other studies on country's language translation of ISCIPBDS are published. The Italian version validation differs from the recent Korean one in the following points: (a) the ISCIPBDS version II instead of the firth one has been translated, (b) the data recording, in the present study, was done in a multicenter modality, (c) some of the SCI persons were hospitalized instead of community-dwelling people, (d) the examiners were physicians instead of occupational therapists [37].

A good interrater agreement based on the values of ICC $>0.7$ and values of $\kappa>0.6$ was obtained in terms of number of pain, type of pain, pain intensity, correspondence of pain localization, the value of the pain interference on day-to-day activities, and overall mood and night's sleep.

In conclusion, the translation of the ISCIPBDS for Italian persons was presented: the interrater reliability of the translated version of ISCIPBDS is high; therefore, such a tool can be used in the clinical practice.

Acknowledgements This study was partially funded by the Italian Ministry of Health under the framework of "Bando Ricerca Finalizzata e Giovani Ricercatori 2011-2012", project "Clinical and healthcare strategies for improving quality of life in persons affected by spinal cord injuries: Tuscany regional network and use of innovative technologies device", Grant RF-2011-02346770. The Società Italiana Midollo spinale (SIMs), which is the Italian affiliate society at the International Spinal Cord Society (ISCoS) promoted the work of IPDS Italian translation and the Italian version of the test will be published on SIMs website to be freely utilized by the physicians involved in the SCI care.

Research Partners G. Stampacchia (Spinal Cord Injury Unit, Pisa University Hospital, Pisa, Italy), A. Gerini (Spinal Cord Injury Unit, Pisa University Hospital, Pisa, Italy), C. D’Avino (Spinal Cord Injury Unit, Pisa University Hospital, Pisa, Italy), A. Massone (Spinal Unit, Pietra Ligure Public Hospital, Savona, Italy), C. Pistarini (Pavia Institute of Rehabilitation I.R.C.C.S, Pavia, Italy), I. B. Aiachini (Pavia Institute of Rehabilitation I.R.C.C.S, Pavia, Italy), R. Formica (Pavia Institute of Rehabilitation I.R.C.C.S, Pavia, Italy), C. Bonavita (Montecatone Institute of NeuroRehabilitation, Bologna, Italy), I. Baroncini (Montecatone Institute of NeuroRehabilitation, Bologna, Italy), T. Giovannini (Montecatone Institute of NeuroRehabilitation, Bologna, Italy), M. Brambilla (Spinal Unit, Sondalo Public Hospital, Sondrio, Italy), G. Campus (Spinal Unit, Cagliari Public Hospital, Cagliari, Italy), G. Del Popolo (Spinal Unit, Firenze University Hospital, Firenze, Italy), V. Zidarich (Spinal Unit, Firenze University Hospital, Firenze, Italy), M.P. Onesta (Spinal Unit, Catania Public Hospital, Catania, Italy), M. Pennisi (Spinal Unit, Catania Public Hospital, Catania, Italy), R. Mashke (Spinal Unit, Perugia University Hospital, Perugia, Italy), M.C. Pagliacci (Spinal Unit,
Perugia University Hospital, Perugia, Italy), V. Cicioni (Spinal Unit, Perugia University Hospital, Perugia, Italy), S. Petrozzino (Spinal Unit, Alessandria Public Hospital, Alessandria, Italy), M. Marchioni (Spinal Unit, Alessandria Public Hospital, Alessandria, Italy).

Author contributions GS was responsible for designing the protocol, writing the protocol and report, conducting the search, interpreting the results. She also has performed the translation of the study's scales from English to Italian language. Eventually she wrote the test of the scientific paper. AM has performed the translation of the study's scales from English into Italian language and was responsible for collecting data from Pietra Ligure Spinal Cord Unit. AG was responsible for collecting data from Pisa Spinal Cord Unit and to accept the records posted from the Ten Centers participating in the study. EB was responsible for creating "summary of findings" tables and figures. SM was responsible for extracting and analysing data and has collaborated in the writing of the paper.

\section{Compliance with ethical standards}

Ethics approval We certify that all applicable institutional and governmental regulations concerning the ethical use of human volunteers were followed during the course of this research. The Local Ethical Committee approved the study $(643,21 / 07 / 2015)$.

Conflict of interest The authors declare that they have no conflict of interest.

\section{References}

1. Lee BB, Cripps RA, Fitzharris M, Wing PC. The global map for traumatic spinal cord injury epidemiology: update 2011, global incidence rate. Spinal Cord. 2014;52:110-6.

2. Middleton JW, Dayton A, Walsh J, Rutkowski SB, Leong G, Duong S. Life expectancy after spinal cord injury: a 50-year study. Spinal Cord. 2012;50:803-11.

3. Rintala DH, Loubser PG, Castro J, Hart KA, Fuhrer MJ. Chronic pain in a community based sample of men with spinal cord injury: prevalence, severity, and relationship with impairment, disability, handicap, and subjective well-being. Arch Phys Med Rehabil. 1998;79:604-14.

4. Turner JA, Cardenas DD, Warms CA, McClellan CB. Chronic pain associated with spinal cord injuries: a community survey. Arch Phys Med Rehabil. 2001;82:501-9.

5. Widerstrom-Noga EG, Felipe-Cuervo E, Yezierski RP. Relationships among clinical characteristics of chronic pain after spinal cord injury. Arch Phys Med Rehabil. 2001;82:1191-7.

6. Siddall PJ, McClelland JM, Rutkowski SB, Cousins MJ. A longitudinal study of the prevalence and characteristics of pain in the first 5 years following spinal cord injury. Pain. 2003;103:249-57.

7. Jensen MP, Hoffman AJ, Cardenas DD. Chronic pain in individuals with spinal cord injury: a survey and longitudinal study. Spinal Cord. 2005;43:704-12.

8. Dijkers M, Bryce T, Zanca J. Prevalence of chronic pain after traumatic spinal cord injury: a systematic review. J Rehabil Res Dev. 2009;46:13-29.

9. Hoffman JM, Bombardier CH, Graves DE, Kalpakjian CZ, Krause JS. A longitudinal study of depression from 1 to 5 years after spinal cord injury. Arch Phys Med Rehabil. 2011;92:411-8.

10. van Leeuwen CM, Post MW, van Asbeck FW, Bongers-Janssen $\mathrm{HM}$, van der Woude $\mathrm{LH}$, de Groot $\mathrm{S}$, et al. Life satisfaction in people with spinal cord injury during the first five years after 
discharge from inpatient rehabilitation. Disabil Rehabil. 2012;34:76-83.

11. Donnelly C, Eng JJ. Pain following spinal cord injury: the impact of community reintegration. Spinal Cord. 2002;43:278-82.

12. Finnerup NB, Baastrup C. Spinal cord injury pain: mechanisms and management. Curr Pain Headache Rep. 2012;16:207.

13. Middleton J, Tran Y, Craig A. Relationship between quality of life and self-efficacy in person with spinal cord injury. Arch Phys Med Rehabil. 2007;88:1643-8.

14. Marcondes BF, Sreepathi S, Markowski J, Nguyen D, Stock SR, Carvalho $\mathrm{S}$, et al. Pain severity and mobility one year after spinal cord injury: a multicenter cross sectional study. Eur J Phys Rehabil Med. 2016;52:630-6.

15. Bryce TN, Biering-Sørensen F, Finnerup NB, Cardenas DD, Defrin R, Lundeberg $\mathrm{T}$, et al. International Spinal Cord Injury Pain Classification: part I. Background and description. Spinal Cord. 2012;50:413-7.

16. Bryce TN, Biering-Sørensen F, Finnerup NB, Cardenas DD, Defrin R, Ivan E, et al. International Spinal Cord Injury Pain (ISCIP) Classification: Part 2. Initial validation using vignettes. Spinal Cord. 2012;50:404-12.

17. Siddall PJ, Yezierski RP, Loeser JD. Pain following spinal cord injury: clinical features, prevalence and taxonomy. IASP Newslett. 2001;3:3-7.

18. Widerstrom-Noga E, Biering-Sorensen F, Bryce T, Cardenas DD, Finnerup NB, Jensen MP, et al. The International Spinal Cord Injury Pain Basic Data Set. Spinal Cord. 2008;46:818-23.

19. Bouhassira D, Attal N, Alchaar H, Boureau F, Brochet B, Bruxelle $\mathrm{J}$, et al. Comparison of pain syndromes associated with nervous or somatic lesions and development of a new neuropathic pain diagnostic questionnaire (DN4). Pain. 2005;114:29-36.

20. Bennett M. The LANSS Pain Scale: the Leeds assessment of neuropathic symptoms and signs. Pain. 2001;92:147-57.

21. Krause SJ, Backonja MM. Development of a neuropathic pain questionnaire. Clin J Pain. 2003;19:306-14.

22. Freynhagen R, Baron R, Gockel U, Tölle TR. painDETECT: a new screening questionnaire to identify neuropathic components in patients with back pain. Curr Med Res Opin. 2006;22:1911-20.

23. Portenoy R. Development and testing of a neuropathic pain screening questionnaire: ID pain. Curr Med Res Opin. 2006;22:1555-65.

24. Melzack R, Torgerson WS. On the language of pain. Anesthesiology. 1971;34:50-9.
25. Widerström-Noga E, Biering-Sørensen F, Bryce TN, Cardenas DD, Finnerup NB, Jensen MP, et al. The International Spinal Cord Injury Pain Basic Data Set (version 2.0). Spinal Cord. 2014;52:282-6.

26. Biering-Sørensen F, Alexander MS, Burns S, Charlifue S, DeVivo $\mathrm{M}$, Dietz V, et al. Recommendations for translation and reliability testing of International Spinal Cord Injury Data Sets. Spinal Cord. 2011;49:357-60.

27. Kirshblum SC, Burns SP, Biering-Sorensen F, Donovan W, Graves DE, Jha A, et al. International standards for neurological classification of spinal cord injury (Revised 2011). J Spinal Cord Med. 2011;34:535-46.

28. Pagliacci MC, Celani MG, Zampolini M, Spizzichino L, Franceschini M, Baratta S, et al. An Italian Survey of Traumatic Spinal Cord Injury. The Gruppo Italiano Studio Epidemiologico Mielolesioni Study. Arch Phys Med Rehabil. 2003;84:1266-75.

29. Citterio A, Franceschini M, Spizzichino L, Reggio A, Rossi B, Stampacchia G, et al. Nontraumatic spinal cord lesions: an italian survey. Arch Phys Med Rehab. 2004;85:1483-7.

30. De Vivo MJ. Epidemiology of traumatic spinal cord injury: trends and future implications. Spinal Cord. 2012;50:365-72.

31. Jain NB, Ayers GD, Peterson EN, Harris MB, Morse L, O'Connor $\mathrm{KC}$, et al. Traumatic spinal cord injury in the United States, 1993-2012. JAMA. 2015;313:2236-43.

32. Varela-Lage C, Alcobendas-Maestro M, Luque-Ríos I, EsclarínDe Ruz A, Talavera-Díaz F, Ceruelo-Abajo S. Spinal cord injury in patients over 65 years of age. Rev Neurol. 2015;60:490-4.

33. Ferro S, Cecconi L, Bonavita J, Pagliacci MC, Biggeri A, Franceschini M. Incidence of traumatic spinal cord injury in Italy during 2013-2014: a population-based study. Spinal Cord. 2017. https://doi.org/10.1038/sc.2017.88.

34. Pagliacci MC, Celani MG, Zampolini M, Spizzichino L, Franceschini M, Baratta $\mathrm{S}$, et al. Spinal cord lesion management in Italy: a 2-year survey. Spinal Cord. 2003;1:620-8.

35. van Gorp S, Kessels AG, Joosten EA, van Kleef M, Patijin J. Pain prevalence and its determinants after spinal cord injury: a sistematic review. Eur J Pain. 2015;19:5-14.

36. Müller R, Brinkhof MW, Arnet U, Hinrichs T, Landmann G, Jordan X, et al. Prevalence and associated factors of pain in the Swiss spinal cord injury population. Spinal Cord. 2017; 55:346-54.

37. Kim HR, Kim HB, Lee BS, Ko HY, Shin HI. Interrater reliability of the Korean version of the International Spinal Cord Injury Basic Pain Data Set. Spinal Cord. 2014;52:855-8. 